\title{
MODEL OF METHODOLOGICAL PROCESS OF TEACHING ON INFORMATION AND COMMUNICATION TECHNOLOGIES
}

\author{
Ratko Ivković1 ${ }^{1}$ Mile Petrović ${ }^{1}$, Petar Spalević ${ }^{1}$, Ivana Milosević ${ }^{2}$ Dejan Rančić ${ }^{3}$ \\ ${ }^{1}$ Faculty of Technical Sciences in Kosovska Mitrovica, University of Pristina, \\ ${ }^{2} \mathrm{High}$ school of Electrical Engineering and Computers, Belgrade \\ ${ }^{3}$ Faculty of Electronics, University of Nis
}

\begin{abstract}
:
This paper presents a suggestions of improving educational process, at the study of "information and communication technologies" teaching programs, which specifically deal with the scientific field of audio and video technology. Program package Blender was presented, which in its palette of tools offers the possibility for simulation of the middle class video system. Blender provides high-quality interactive content, and also the ability to support the formation of virtual classrooms and laboratories and the ability to efficiently evaluate the impact of teaching and assessment of students during the teaching process. Described software supports and provides a continuous and interactive process of theoretical teaching. The above mentioned performance of Blender software allow successful implementation of learning at a distance in the field of audio and video technology, as an additional service in the teaching process.
\end{abstract}

\author{
Key words: \\ e-learning, \\ Blender, \\ audio and video system \\ simulation.
}

\section{INTRODUCTION}

New technological changes and new demands in the labor market have affect the educational process. This influence is reflected in the type and quality of knowledge [1].

As part of improving the quality of higher education systems includes e-learning [2]. The advantages of elearning over traditional studies at University is in reducing the spatial and temporal constraints, then the cost of housing and transportation, as opposed to increasing the capacity and number of audience [3].

The convenience of e-learning is the conciseness of the selected materials and standardized procedures for using relevant materials, also using audio and video multimedia content.

At the same time permanent contact with information and communication technology environment contributes to the development of creative skills and specific practical skills needed for future career development [4].

However, this system had serious gaps, such as lack of teamwork, lack of practice, lack of active communication with students, as well as many others.

This work has provided concrete solutions on which way it can be partially eliminated the lack of practical work in the field of audio and video technology [5].
Functioning of audio and video systems are difficult to explain without the real practice. The practice must demonstrate the whole system audio and video system from source to distribution. Software solutions in this area are rare, most of them do not have an open source, free license and very expensive [6], [7].

Blender is a free and open source software for $3 \mathrm{D}$ animation and simulation. Blender is cross-platform based on OpenGL and runs equally well on Windows, Linux and Macintosh computers [8].

Blender works under the GNU General Public License (GPU), and this license involves:

- Free using Blender, for any purpose,

- Free distribution of Blender software,

- Changing of Blender software,

- Distribute changed version of Blender software.

As an example in this paper was used 2.69 version of the software, which is available on the website http://www. blender.org.

\section{BLENDER - OPERATING ENVIRONMENT}

Before starting work in Blender software package, it is necessary to set operating environment for working with audio and video parameters. Setting the operating environment was very simple and is performed in several steps. 
The first step is switching from the environment for 3D animation to simulation system environment. The new environment can be found in the drop-down menu of Info panel called Node Editor (shown in Figure 1).

After selecting the Node Editor environment it is necessary to choose a Full Screen option. Right-click on the top tab at the programming environment (Header), and select a new option Maximize Area (shown in Figure 2).
In the third step it's performed the setting within the Node editor environments and preparing for the operation. By marking options number 3 and number 4 it includes the graphical simulator audio and video systems.

By including the last option within number 5 in Figure 3, drop-down menu opens which contains all the elements of audio and video system is divided into related areas.

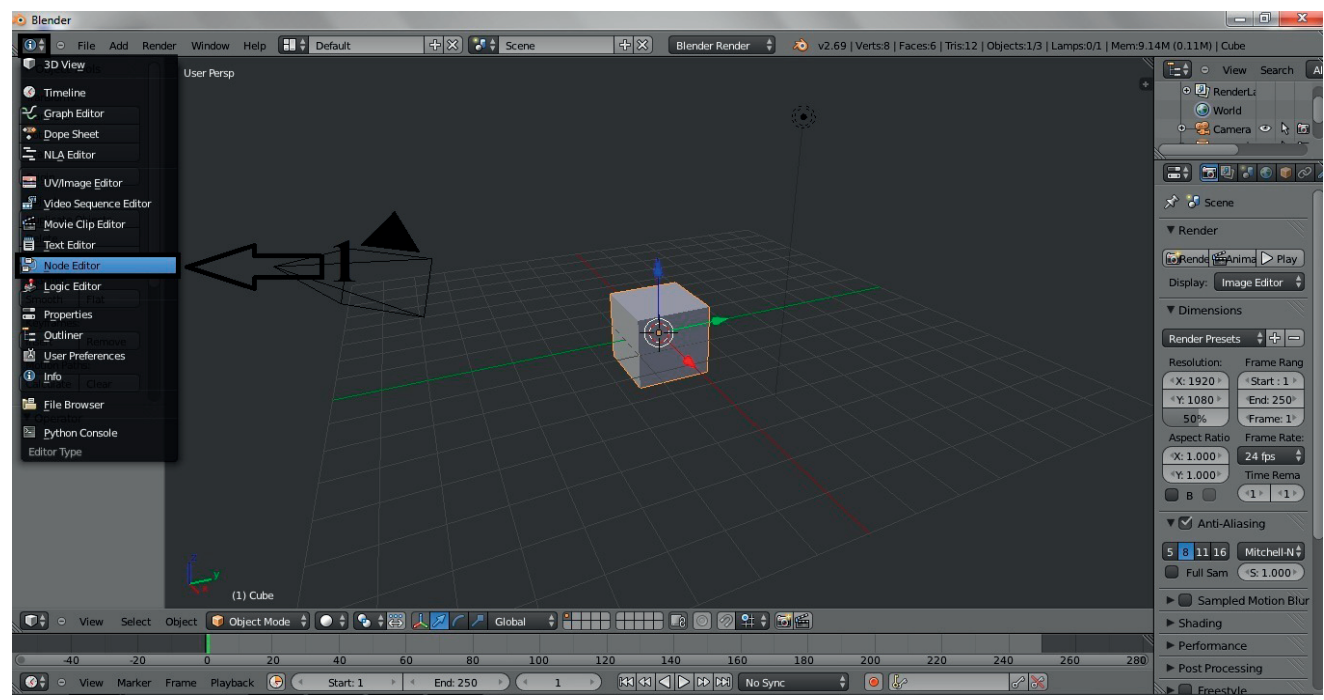

Fig. 1. Switching from 3D environment to simulation system environment

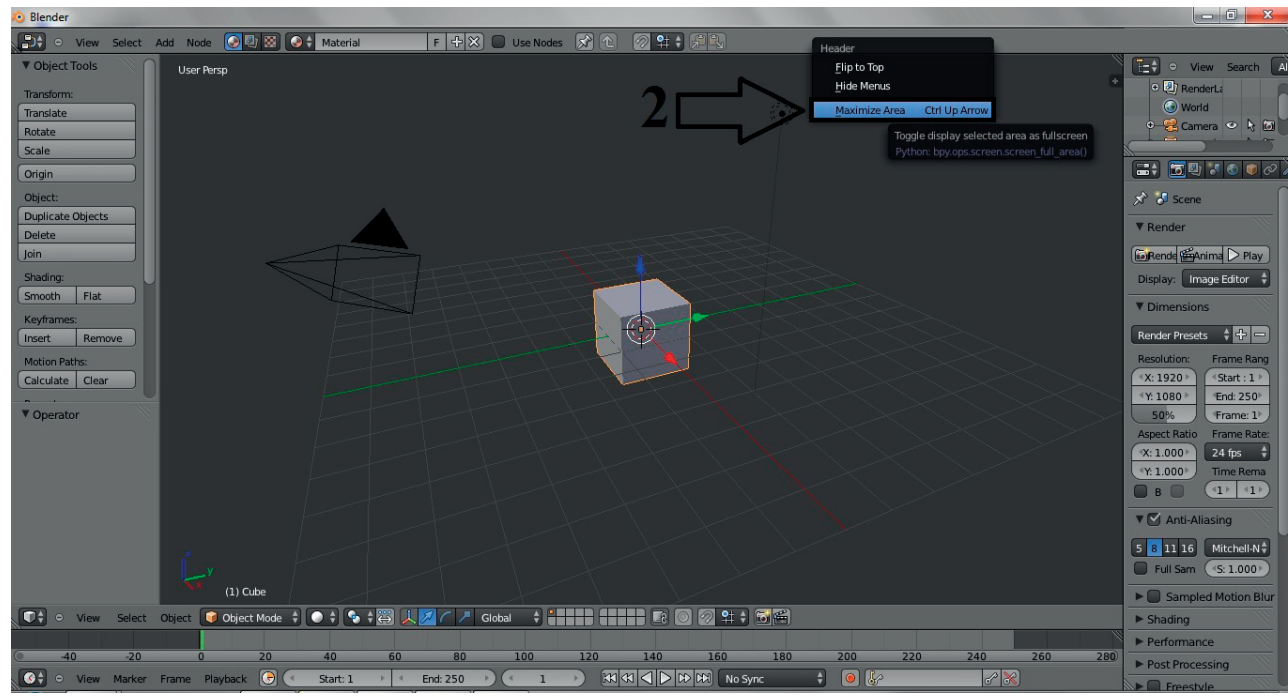

Fig. 2. Full Screen mode in Node Editor Options

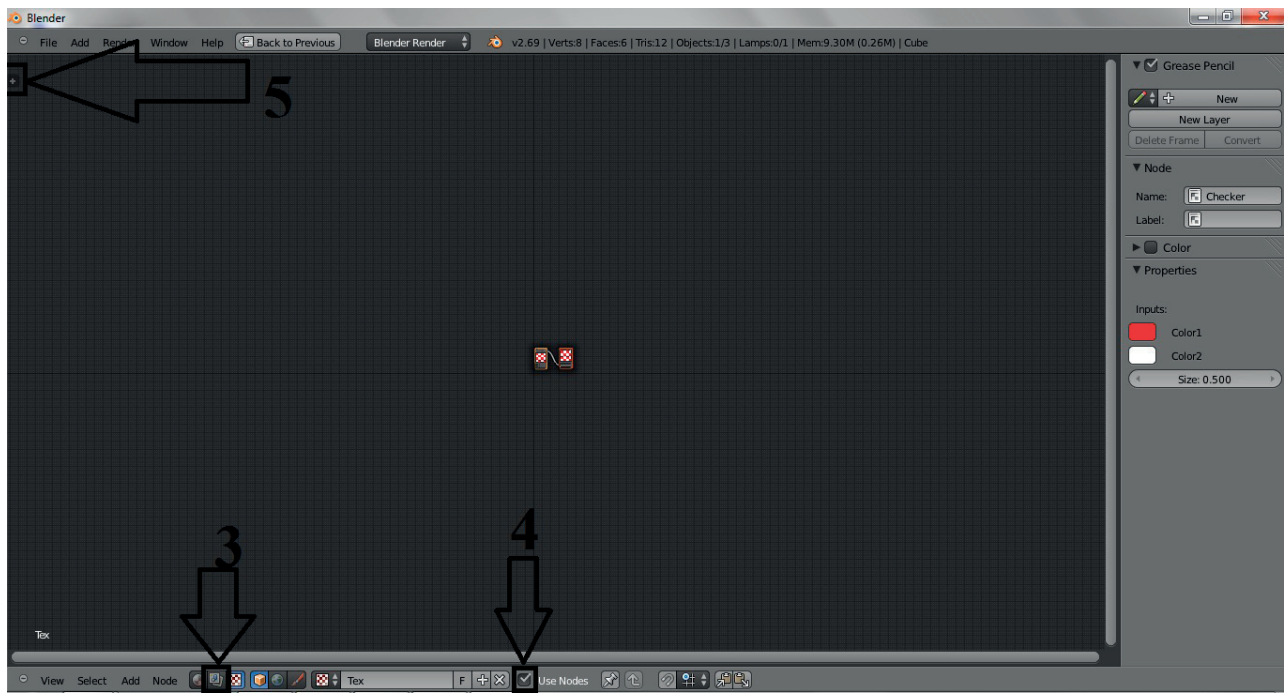

Fig. 3. Setting the Node Editor environment 


\section{BLENDER SOFTWARE OPTIONS IN THE NODE EDITOR OPTION}

After full adjustment of Blender simulation software of audio and video systems, all elements of the system are given in the drop-down menu and divided into areas as shown in Figure 4.

Complete groups can be divided into three groups: Input, Output, and group operations of processing audio and video signals.

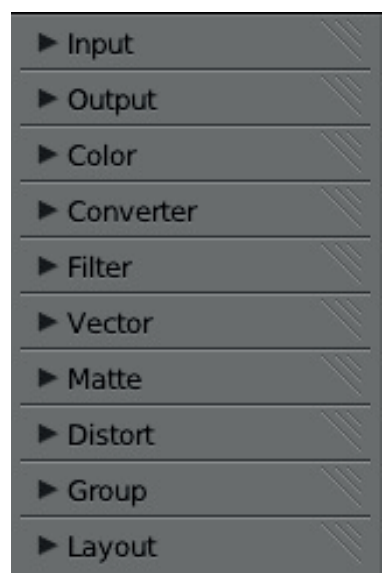

Fig. 4. Elements of the system are divided into related areas

Input represent start of some system. Under first option, Input can be defined to simulate the types of sources: Render Layers, Image, Movie Clip, Mask, RGB, Value, Texture, Bokeh Image, Time and Track Position. As it's shown, Blender provides a wide range of sources for the system simulation.

Output section defines the types of system outputs: Composite, Viewer, Split Viewer, File Output, Levels. It means, defined outputs can be output for only one signal, multi signals or defined by level of already loaded and processed signals.

Group of operations processing audio and video signals are divided into:
- Range of tools for managing color image signal and videos (Color).

- Range of tools that are used to convert the signal (Convertor).

- Range filter (Filter).

- Control signals by vector (Vector).

- The range of tools for the management of light, colors, masks, etc. (Matte).

- The range of tools Corp, Rotate, Flip, etc. (Distort).

Beyond all this, program provides an ability of grouping selected set of tools in the desired group (Group), as well as their definition into levels (Layout).

\section{EXAMPLES}

A wide spectrum of tools at the Blender program gives a numerous sets of possible simulation of audio and video system. This paper work represent several possible audio and videos system realization.

Any system consists three parts: input, processing and output of the system. In the case of audio and video systems simulation in Blender software package input can be defined as: image, texture or video clip.

Practically speaking, it can be an output from the camera or video camera. On the other hand, the output of the whole system may be signal which we give to the distribution network for broadcasting.

In the example shown in Figure 5 it has been provided an analysis of the RGB image file format.

Once loaded image, it is split into RGB signals by Convertor tools (b), after that each signal it's adjusted with Lift, Gamma and Gain correction tools using the Color Balance (c). After the correction tools image again merged into one RGB signal (d) and filtered by Unsharp filter (s). At the end of this system by using the Output Viewer (f) and marking options Backdrop ( $\mathrm{h}$ ) is displayed on the screen. Also gained image result can be saved by using the File Output tools ( $\mathrm{g}$ ) from group output.

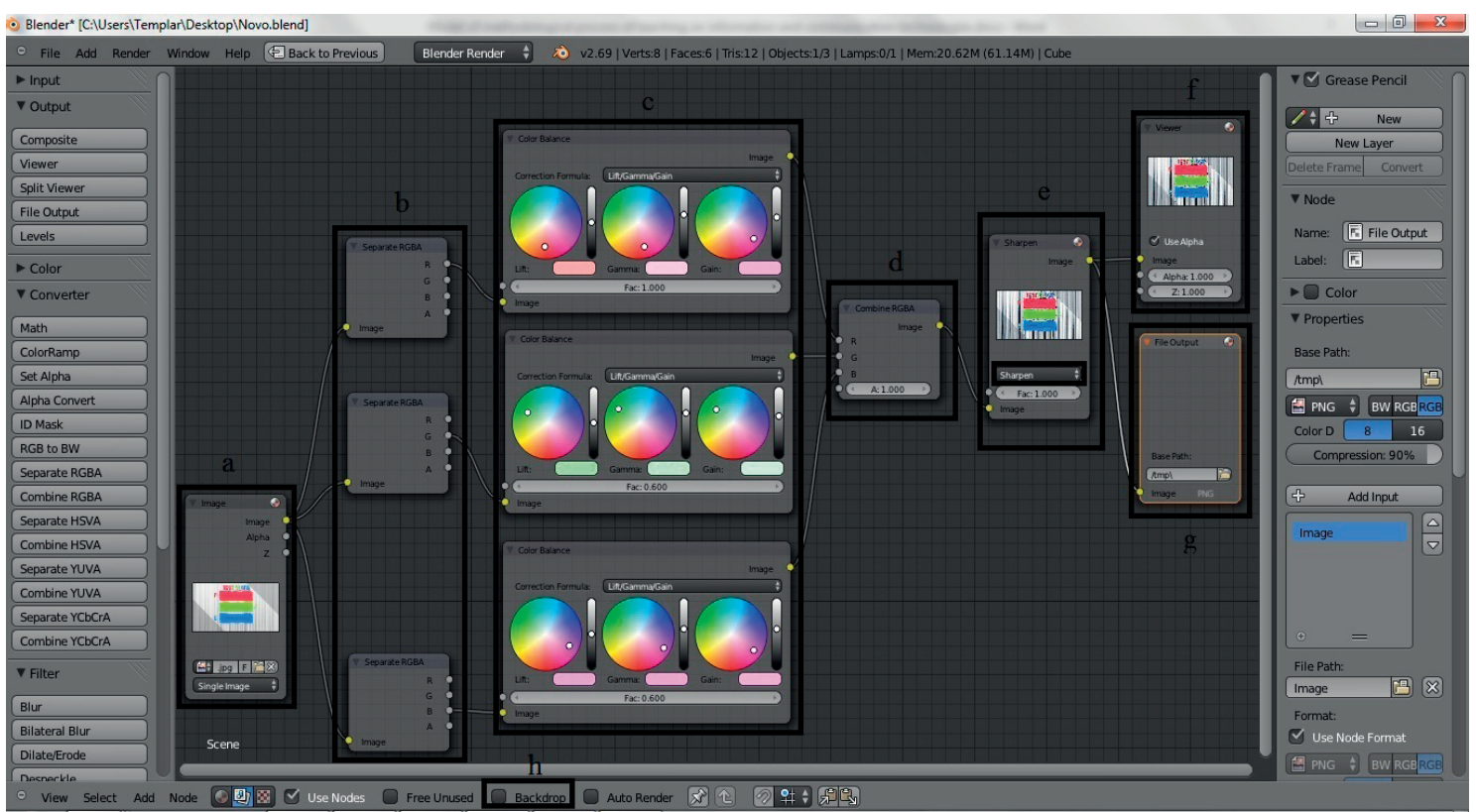

Figure 5. An example of realization of the system using the Blender software 


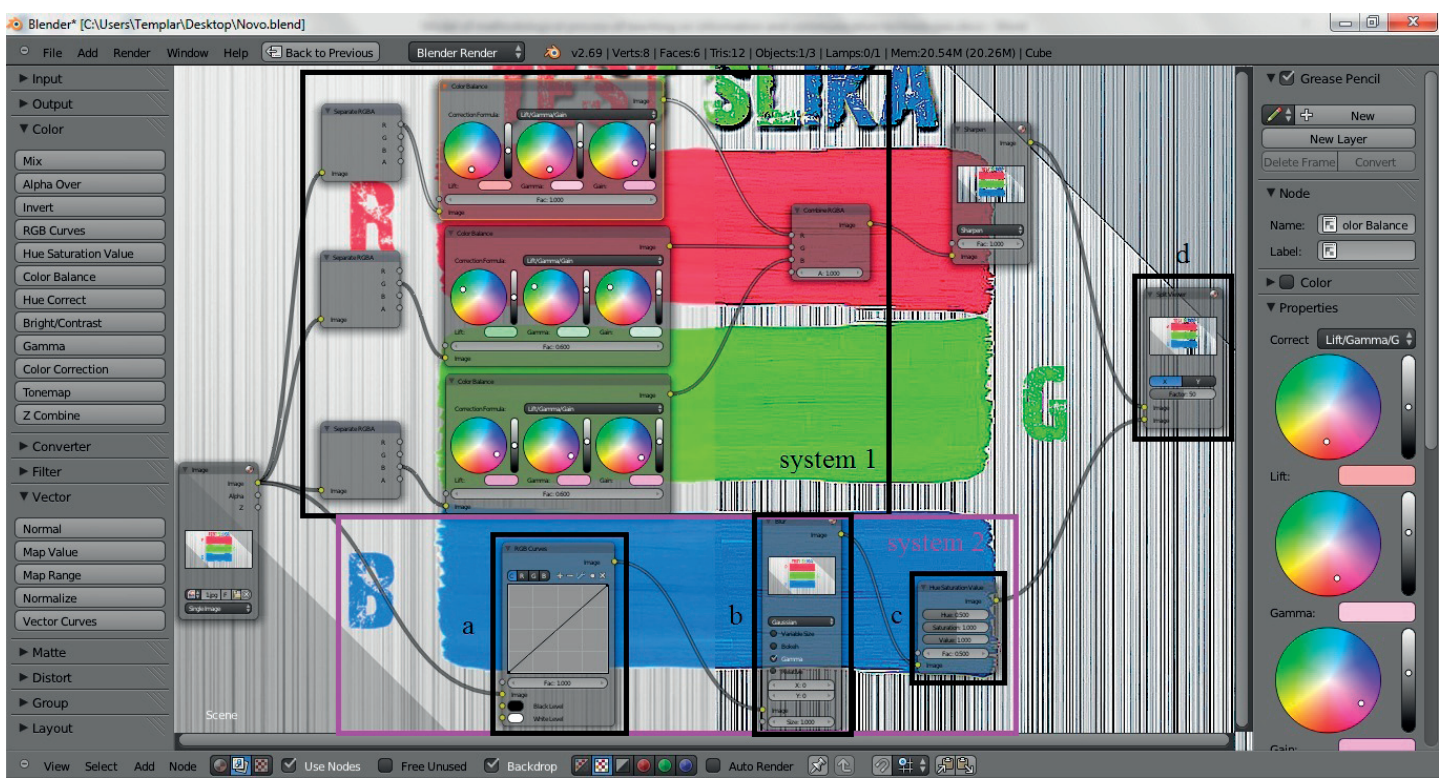

Figure 6. Comparison of two audio and video systems

On the other hand, this system like this can be compared with another created system. It is important to note that it can work with the same source.

Figure 6 gives an insight into the analysis of the two presented systems; on the left side of the background is an image that is obtained by the treatment system 2 , while on the right side of the background is an image obtained by the treatment system 1 .

The first system has been described and is shown in Figure 5. In another system of the first input signal has modified by RGB function curves (a), than, over the signal applied to the Gaussian Blur filter function (b). Over this signal is defined by the value of the Color Saturation HUE (c).

Output of the first and second system is connected to Split Viewer (d), which simulate multi view screen in the audio and video system.

\section{CONCLUSION}

Program tutorial and example should provide in organizing trainings that can be used to simulate the audio and video systems. Wide set of tools for processing also provides a large number of possible system for simulation, which is the positive side, because of that it can be used with a large number of students.

The software is free and has an open license to use. In this way, anyone who is able and wants can upgrade program and adapt it to its needs. Even the license permits to take and distribute modified versions of the software. Another positive aspect of Blender software is that the present circumstances do not require a lot of hardware and software resources, and it is available on all operating systems.

Projects worked in package Blender software for the simulation of audio and video systems do not exceed 1 $\mathrm{MB}$, hence they are very handy for sending over the Internet.

At the end, control of the received projects can be prepared on the basis of Properties option, which gives in- sight into the date and time of creation and modification of the project, as well as data on which computer where the file is created.

\section{Acknowledgment}

This work was done within the research project of the Ministry of Science and Technological Development of Serbia TR35026 and 47016.

\section{REFERENCES}

[1] A. Shirley, "E-learning developments and experiences." Education + Training 43, no. 4/5, 2001, pp. 240-248.

[2] C. Fallon and S. Brown, e-Learning Standards: A Guide to Purchasing, Developing, and Deploying Standards-Conformant E-Learning, St. Lucie Press, 2002.

[3] P. Poulova, B. Tesarova and M. Maneonova, "Efficiency Comparison of eLearning Supported Instruction to Traditional University Courses in the Subject of Database Systems 2," in EDUCATION'10 Proceedings of the 7th WSEAS international conference on Engineering education, 2010.

[4] G. Dimić, K. Kuk, I. Petrović, "Unapređenje nastavnog procesa kao jedna od varijanti e-learning modela", InfotehJahorina Vol. 7, Ref. E- III-7, 2008, pp. 493-497.

[5] D. Pevac, "Iskustva sa koriščenjem class server LMS softvera u primeni e-learning metode u procesu modernizacije obrazovanja", Zbornik radova Infoteh-Jahorina, Vol. 6, Ref. E-IV-5, 2007, pp. 480-485.

[6] I. Kostić-Kovačević, J. Gavrilović, "Inkorporiranje obrazovnih softvera za dinamičku matematiku u sistem za učenje na daljinu", Zbornik radova Infoteh-Jahorina Vol. 10, Ref. E-V-7, 2011, pp. 780-783.

[7] S. Hou, S.-h. Chen, "Research on Applying the Theory of Blending Learning on Access Database Programming Course Teaching," in 2nd international Conference on Education Technology and Computer (ICETC), Shanghai, China, 2010.

[8] Blender software packet. Available on web address: www. blender.org. 